\title{
Quality of life in Parkinson's disease patients: progression markers of mild to moderate stages
}

\author{
Qualidade de vida de indivíduos com doença de Parkinson: marcadores da progressão da \\ fase leve para moderada
}

Raissa Carla Moreiraํ, Marise Bueno Zonta², Ana Paula Serra de Araújo ${ }^{3}$, Vera Lúcia Israel4, Hélio A. G. Teive

\begin{abstract}
Objective: To investigate which factors are associated with the quality of life decline in Parkinson's disease patients from mild to moderate stages. Methods: The Unified Parkinson's Disease Rating Scale and Parkinson's Disease Questionnaire-39 were used to evaluate clinical/functional data and the quality of life. Results: The markers of clinical/functional worsening were drooling ( $p<0.004)$, need for assistance with hygiene $(p=0.02)$, greater freezing frequency $(p=0.042)$, bradykinesia $(p=0.031)$, greater intensity of the resting tremor $(p=0.035)$ and "pill rolling" ( $p=0.001)$. The decline in quality of life was related to stigma $(p=0.043)$, greater impairment in cognition ( $p=0.002)$, mobility ( $p=0.013)$ and for daily living activities ( $p=0.05)$, and was considered more significant in men, married, older individuals, and those with a longer time of disease. Conclusions: The quality of life worsening markers at the moderate stage were related to stigma, worsening of cognition, and to greater impairment in mobility and daily living activities.
\end{abstract}

Keywords: Parkinson disease; quality of life; surveys and questionnaires.

\section{RESUMO}

Objetivo: Verificar os fatores relacionados ao declínio clínico/funcional e de Qualidade de Vida de indivíduos com Doença de Parkinson, da fase leve para moderada. Métodos: Foram utilizadas as escalas Unified Parkinson's Disease Rating Scale and Parkinson's Disease Questionnaire-39 (UPDRS e PDQ-39) para avaliação clínico/funcional e de qualidade de vida Resultados: Os marcadores de piora clínico/funcional na fase moderada foram: sialorréia ( $p<0,004)$, necessidade de ajuda para higiene ( $p=0,02)$, maior frequência do "freezing" $(p=0,042)$, bradicinesia $(p=0,031)$ e maior intensidade do tremor de repouso $(p=0,035)$ e bater dos dedos $(p=0,001)$. 0 declínio da qualidade de vida esteve relacionado ao estigma $(p=0,043)$, ao maior comprometimento da cognição $(p=0,002)$, da mobilidade ( $p=0,013)$ e da independência para realizar as atividade de vida diária (AVD's) ( $p=0,05$ ), sendo mais importante nos homens, nos casados, nos indivíduos com maior idade e naqueles com maior tempo de evolução da doença. Conclusão: Os marcadores de piora da qualidade de vida na fase moderada estiveram relacionados ao estigma, à piora da cognição, ao maior comprometimento para mobilidade e AVD's.

Palavras-chave: doença de Parkinson; qualidade de vida; inquéritos e questionários.

Parkinson's disease (PD) is a chronic degenerative disease of the central nervous system that evolves slowly and progressively and is characterized by bradykinesia, muscle rigidity and resting tremor among other motor signs and symptoms ${ }^{1,2}$. Quality of life is significantly impaired not only by motor symptoms, but also by non-motor symptoms such as depression, anxiety, pain, constipation, hyposmia and sleep disturbances ${ }^{3,4}$.

There are few studies on the incidence and prevalence of PD in Brazil; however, the most recent study shows that the disease affects $3.3 \%$ of Brazilians over the age of 60 years ${ }^{4}$. One of the concerns when treating PD patients is to improve their quality of life. This includes their physical, functional and emotional well-being, their degree of independence and their family relationships, as well as social, economic and political aspects of their lives ${ }^{5,6}$.

A decline in quality of life in individuals with PD has been associated with worsening motor symptoms and the combination of neurodegenerative phenomena, psychological suffering and stigma associated with the disease ${ }^{7}$. However,

1 Universidade Federal do Paraná, Curitiba PR, Brasil;

2Universidade Federal do Paraná, Hospital de Clínicas, Departamento de Reabilitação, Curitiba PR, Brasil;

${ }^{3}$ Secretaria Municipal de Saúde, Prefeitura Municipal de Guarapuava, Guarapuava PR, Brasil;

«Universidade Federal do Paraná, Departamento de Fisioterapia, Curitiba PR, Brasil;

5Universidade Federal do Paraná, Departamento de Medicina, Curitiba PR, Brasil.

Correspondence: Raissa Carla Moreira; Rua XV de Novembro, 1299; 80060-000 Curitiba PR, Brasil; E-mail: fisioraissa@hotmail.com

Conflict of interest: There is no conflict of interest to declare.

Received 25 November 2016; Received in final form 31 March 2017; Accepted 11 May 2017. 
in-depth studies are required to differentiate between the impact of PD at different stages of the disease $e^{6,7}$.

The objective of this study was to investigate which factors are associated with clinical/functional decline and a decline in quality of life in individuals with mild and moderate PD.

\section{METHODS}

The study was a cross-sectional one, and data on individuals who had been diagnosed with PD, and were registered at the Paraná Association for Individuals with Parkinson's Disease (APPP), were collected from January to May 2012 in the city of Curitiba, in the state of Paraná, Brazil. The convenience sample comprised 100 individuals of both sexes between the ages of 60 and 80 years with impairment rated between 1 and 3 on the Hoehn and Yahr (HY) scale. The group with mild PD (MIG), consisting of 50 individuals classified as HY 1-2, was compared with the group with moderate PD (MOG), which consisted of 50 individuals classified as HY $3^{8,9}$. The demographic data are shown in Table 1.

Individuals were only included in the study if they agreed to take part, signed a voluntary informed-consent form and were present on the days when the data were collected. Individuals with dementia or any other concomitant neurodegenerative disease were excluded. The study started after it had been approved by the Human Research Ethics

Table 1. Comparison of mild Parkinson's disease and moderate Parkinson's disease groups in terms of gender, age, race, marital status and level of education.

\begin{tabular}{|c|c|c|c|}
\hline Variable & $\frac{\text { Mild }}{\mathrm{n}(\%)}$ & $\frac{\text { Moderate }}{n(\%)}$ & p-value* \\
\hline \multicolumn{4}{|l|}{ Gender } \\
\hline Female & $28(56)$ & $22(44)$ & \\
\hline Male & $22(44)$ & $28(56)$ & 0.317 \\
\hline \multicolumn{4}{|l|}{ Age (years) } \\
\hline $60-65$ & $11(22)$ & $13(26)$ & \\
\hline $66-70$ & $16(32)$ & $8(16)$ & \\
\hline $71-75$ & $10(20)$ & $17(34)$ & \\
\hline $76-80$ & $13(26)$ & $12(24)$ & 0.196 \\
\hline \multicolumn{4}{|l|}{ Race } \\
\hline White & $45(90)$ & $46(92)$ & \\
\hline Yellow/Black & $5(10)$ & $4(8)$ & 1 \\
\hline \multicolumn{4}{|l|}{ Marital status } \\
\hline Married & $32(64)$ & $38(76)$ & \\
\hline Separated/widow(er)/single & $18(36)$ & $12(24)$ & 0.275 \\
\hline \multicolumn{4}{|l|}{ Level of education } \\
\hline Primary education (incomplete) & $9(18)$ & $11(22)$ & \\
\hline Primary education (complete) & $27(54)$ & $19(38)$ & \\
\hline $\begin{array}{l}\text { High school (complete or } \\
\text { incomplete) }\end{array}$ & $5(10)$ & $8(16)$ & \\
\hline $\begin{array}{l}\text { Third-level education (complete } \\
\text { or incomplete) }\end{array}$ & $9(18)$ & $12(24)$ & 0.438 \\
\hline
\end{tabular}

Committee of the Hospital de Clínicas, Federal University of Paraná (ref. no. 2654.261/2011-11).

The evaluation protocol covered clinical history and demographic, clinical, functional and quality-of-life data. The demographic data were collected in the interview, and the clinical history was obtained from the patients' medical records. Clinical/functional data were obtained by applying the Unified Parkinson's Disease Rating Scale (UPDRS) (activities of daily living [ADL] and motor examination sections) ${ }^{9}$. Quality-of-life data were collected with the Parkinson's Disease Questionnaire (PDQ-39) ${ }^{10}$. The UPDRS and PDQ-39 were filled out by the researcher.

The UPDRS evaluates an individual's signs, symptoms and activities based on self-reports and clinical observation and consists of 42 questions in four sections. The ADL and motor examination sections were analyzed.

The PDQ-39 is an easily-applied, widely-used questionnaire on quality of life in individuals with $\mathrm{PD}$, which evaluates the individual's health in the previous month. The 39 multiple choice questions cover eight domains and have five possible answers: never, occasionally, sometimes, often and always ${ }^{11,12}$. The questionnaire is normally filled out by the individual. However, it was decided to complete it with the help of the researcher during a one-to-one interview because of the possibility of some of the respondents having a limited education or difficulty writing due to the motor symptoms of the disease.

Information on HY staging was obtained from the patients' medical records at APPP. The influences of age, gender, education, marital status and disease duration on quality of life and ADL and motor examination scores were also examined.

\section{Statistics}

Quantitative variables were described in terms of their mean, median, minimum, maximum and standard deviation, and qualitative variables in terms of frequency and percentage. The non-parametric Mann-Whitney test was used to compare the two groups (MIG and MOG) based on the UPDRS and PDQ-39 scores.

Spearman's coefficient was used to evaluate the correlation between the UPDRS and PDQ-39 scores and HY staging and between the UPDRS and the PDQ-39 scores. The significance level was set at $\mathrm{p}<0.05$. The data were analyzed with Statistica 8.0.

\section{RESULTS}

The mean disease duration in the MIG was $3.4( \pm 2.2)$ years and $8.1( \pm 4.7)$ in the MOG. The MOG had greater impairment in the ADL domain (UPDRS). This finding had borderline significance and was particularly noticeable in the increased drooling $(p<0.004)$, greater need for 
assistance with personal hygiene $(p=0.02)$ and increased frequency of freezing $(p=0.042)$ in this group. Although greater impairment was observed in motor examination items in the MOG, this was not statistically significant ( $p=0.220$ ). Nevertheless, when each item in this domain was considered individually, significant differences were

Table 2. Comparison of the mild Parkinson's disease group with the moderate Parkinson's disease group in the activities of daily living and motor-examination sections of the UPDRS items with a statistically significant difference.

\begin{tabular}{|c|c|c|c|c|c|c|}
\hline \multirow{2}{*}{$\begin{array}{l}\text { UPDRS - } \\
\text { ADLs }\end{array}$} & \multirow[t]{2}{*}{ Stage } & \multicolumn{4}{|c|}{$\begin{array}{l}\text { Number of individuals and \% } \\
\text { for each answer }\end{array}$} & \multirow[t]{2}{*}{$p$-value* } \\
\hline & & 0 & 1 & 2 & 3 or 4 & \\
\hline \multirow{2}{*}{ Drooling } & Mild & $24(48)$ & $15(30)$ & $11(22)$ & $0(0)$ & \\
\hline & Moderate & $9(18)$ & $18(36)$ & $19(38)$ & $4(8)$ & $0.004^{\star}$ \\
\hline \multirow{2}{*}{$\begin{array}{l}\text { Personal } \\
\text { hygiene }\end{array}$} & Mild & $5(10)$ & $34(68)$ & $10(20)$ & $1(2)$ & \\
\hline & Moderate & $0(0)$ & $38(76)$ & $6(12)$ & $6(12)$ & $0.020 *$ \\
\hline \multirow{2}{*}{ Freezing } & Mild & $7(14)$ & $23(46)$ & $12(24)$ & $8(16)$ & \\
\hline & Moderate & $8(16)$ & $11(22)$ & $13(26)$ & $18(36)$ & $0.042^{\star}$ \\
\hline \multicolumn{7}{|c|}{ UPDRS - Motor examination } \\
\hline \multirow{2}{*}{$\begin{array}{l}\text { Resting } \\
\text { tremor }\end{array}$} & Mild & $5(10)$ & $30(60)$ & $12(24)$ & $3(6)$ & \\
\hline & Moderate & $1(2)$ & $33(66)$ & $6(12)$ & $10(20)$ & $0.035^{\star}$ \\
\hline \multirow{2}{*}{ Pill-rolling } & Mild & $25(50)$ & $23(46)$ & $2(4)$ & $0(0)$ & \\
\hline & Moderate & $7(14)$ & $39(78)$ & $3(6)$ & $1(2)$ & $0.001 * *$ \\
\hline \multirow{2}{*}{ Bradykinesia } & Mild & $3(6)$ & $21(42)$ & $1(2)$ & $25(50)$ & \\
\hline & Moderate & $1(2)$ & $32(64)$ & $4(8)$ & $13(26)$ & $0.031 *$ \\
\hline
\end{tabular}

UPDRS: Unified Parkinson's Disease Rating Scale. ADLs: Activities of Daily living. Categories 2, 3 and 4 were combined for the statistical analysis. Motor Examination: Categories 3 and 4 were combined for the statistical analysis. ${ }^{*}$ Chi-square test, $p<0.05$. observed in resting tremor $(\mathrm{p}<0.035)$, pill-rolling $(\mathrm{p}<0.001)$ and bradykinesia $(\mathrm{p}<0.031)$ (Table 2$)$.

In the evaluation of quality of life as measured by the PDQ-39, the means of seven of the eight items analyzed were greater in the MOG than in the MIG. These differences were statistically significant in the mobility $(\mathrm{p}<0.013)$, stigma $(\mathrm{p}<0.043)$ and cognition $(\mathrm{p}<0.002)$ domains (Table 3$)$. The difference in the bodily discomfort domain between the groups was not statistically significant, but individual analysis of the items showed that painful muscle cramps and spasms caused significantly more impairment of quality of life in the MOG group ( $p=0.04$ ). The answers to the PDQ-39 for which there was a statistically significant difference between the two groups are shown in Table 4.

There was no correlation between gender and clinical/ functional status or quality of life in individuals in the MIG. In the MOG, a decline in quality of life was associated with a lack of support from friends and family members $(p=0.01)$.

Among married individuals, a decline in quality of life was associated with stigma $(p=0.02)$ in the MOG and with a lack of support from friends and family members in both groups $(\mathrm{p}<0.001)$.

There was no correlation between age and clinical/functional status or quality of life in individuals in the MIG. In the MOG, increasing age was associated with greater dependence in ADLs $(p=0.02)$ and greater cognitive impairment (concentration and memory, $\mathrm{p}=0.01$ ).

Greater disease duration was associated with a decline in quality of life in the ADL (MIG, p = 0.03) and emotional well-being (MOG, $\mathrm{p}=0.01$ ) domains (Table 5).

Table 3. Comparison of quality-of-life scores in the Parkinson's Disease Questionnaire-39 domains for the mild, and moderate Parkinson's disease groups.

\begin{tabular}{|c|c|c|c|c|c|c|c|c|}
\hline Domain & Stage & $n$ & Mean & Median & Minimum & Maximum & $\begin{array}{l}\text { Standard } \\
\text { deviation }\end{array}$ & $p$-value* \\
\hline \multirow{2}{*}{ Mobility } & Mild & 50 & 19.2 & 20.0 & 1.0 & 37.0 & 7.5 & \\
\hline & Moderate & 50 & 23.4 & 23.0 & 10.0 & 38.0 & 7.1 & $0.013^{\star}$ \\
\hline \multirow{2}{*}{ ADLs } & Mild & 50 & 9.4 & 9.0 & 0.0 & 19.0 & 4.6 & \\
\hline & Moderate & 50 & 11.6 & 11.0 & 2.0 & 24.0 & 4.8 & 0.050 \\
\hline \multirow{2}{*}{ Well-being } & Mild & 50 & 10.0 & 12.0 & 0.0 & 26.0 & 5.1 & \\
\hline & Moderate & 50 & 10.5 & 11.0 & 1.0 & 18.0 & 4.4 & 0.724 \\
\hline \multirow{2}{*}{ Stigma } & Mild & 50 & 2.7 & 1.5 & 0.0 & 12.0 & 3.1 & \\
\hline & Moderate & 50 & 3.9 & 2.0 & 0.0 & 18.0 & 3.8 & $0.043^{\star}$ \\
\hline \multirow{2}{*}{ Support } & Mild & 50 & 6.7 & 8.0 & 1.0 & 12.0 & 2.3 & \\
\hline & Moderate & 50 & 7.4 & 8.0 & 2.0 & 11.0 & 2.1 & 0.089 \\
\hline \multirow{2}{*}{ Cognition } & Mild & 50 & 5.8 & 7.0 & 0.0 & 12.0 & 2.6 & \\
\hline & Moderate & 49 & 7.3 & 8.0 & 2.0 & 12.0 & 2.4 & $0.002 *$ \\
\hline \multirow{2}{*}{ Communication } & Mild & 50 & 3.3 & 3.5 & 0.0 & 8.0 & 2.6 & \\
\hline & Moderate & 50 & 3.6 & 4.0 & 0.0 & 8.0 & 2.4 & 0.614 \\
\hline \multirow{2}{*}{ Bodily discomfort } & Mild & 50 & 6.3 & 7.0 & 0.0 & 11.0 & 2.3 & \\
\hline & Moderate & 50 & 6.2 & 6.0 & 2.0 & 10.0 & 1.8 & 0.525 \\
\hline
\end{tabular}

ADLs: Activities of Daily living; * ${ }^{\star}$ tatistically significant difference in the non-parametric Mann-Whitney test at a significance level of $p<0.05$. 
Table 4. Answers in the PDQ-39 domains with statistically significant, or borderline statistically significant differences between the mild, and moderate Parkinson's disease groups.

\begin{tabular}{lc}
\hline PDQ-39 domains & Difference between the MIG and MOG groups \\
\hline Mobility & $p=0.041$ \\
Q1. Have you had difficulty doing the leisure activities you like? & $p=0.052$ \\
Q10. Have you been confined to the house more than you would like? & $p=0.048$ \\
ADLs domain & $p=0.043$ \\
Q5. Have you had difficulty cutting up your food? & $p=0.01$ \\
Q6. Have you had difficulty holding a drink without spilling it? & $p=0.054$ \\
Emotional well-being domain & $p=0.045$ \\
Q5. Have you felt anxious? & $p=0.018$ \\
Q6. Have you felt worried about your future? ( $p=0.054)$ & $p=0.027$ \\
Stigma domain & \\
Q2. Have you avoided situations which involve eating or drinking in public? & $p=0.04$ \\
Cognition domain & \\
\hline Q2. Have you had problems with your concentration? & \\
\hline Q3. Have you felt your memory was bad? & \\
\hline Bodily discomfort domain &
\end{tabular}

MIG: group with mild PD; MOG: group with moderate PD; PDQ-39: Parkinson's disease questionnaire-39.

Table 5. Relation between UPDRS and PDQ-39 domains and disease duration in the mild, and moderate Parkinson's disease groups.

\begin{tabular}{|c|c|c|c|c|}
\hline \multirow{2}{*}{ Variable } & \multicolumn{2}{|c|}{ Mild } & \multicolumn{2}{|c|}{ Moderate } \\
\hline & $r$ & $p$-value & $r$ & $\mathrm{p}$-value \\
\hline ADLs & 0.14 & 0.328 & 0.17 & 0.230 \\
\hline \multicolumn{5}{|l|}{ UPDRS } \\
\hline Motor examination & -0.03 & 0.811 & 0.17 & 0.232 \\
\hline Mobility & -0.05 & 0.742 & 0.19 & 0.188 \\
\hline ADLs & 0.30 & $0.035^{\star}$ & 0.11 & 0.459 \\
\hline Well-being & 0.01 & 0.948 & 0.34 & $0.017 *$ \\
\hline \multicolumn{5}{|l|}{ PDQ-39 } \\
\hline Stigma & 0.12 & 0.414 & -0.05 & 0.729 \\
\hline Support & -0.13 & 0.387 & 0.01 & 0.972 \\
\hline Cognition & 0.15 & 0.311 & 0.27 & 0.060 \\
\hline Communication & 0.06 & 0.681 & 0.24 & 0.087 \\
\hline Bodily discomfort & 0.16 & 0.275 & 0.07 & 0.629 \\
\hline
\end{tabular}

ADLs: activities of daily living; UPDRS: unified Parkinson's disease rating scale. PDQ-39: Parkinson's disease questionnaire-39.

\section{DISCUSSION}

The domain that evaluates independence in ADLs was significantly more affected in patients with moderate PD. This finding corroborates the results reported in the literature, in which mild PD is characterized by complete functionality and moderate PD by functional impairment due to the more severe signs and symptoms, which act as precursors of disability ${ }^{13,14}$.
Detailed analysis of the responses in this domain showed that the need for assistance with personal hygiene together with drooling and more frequent freezing were markers of loss of independence and difficulty living with embarrassment and limited social interaction. Drooling is associated with muscle rigidity and bradykinesia, symptoms that also lead to a greater need for assistance with personal hygiene ${ }^{15}$. For Khoo et al. ${ }^{16}$, non-motor signs such as drooling were common in the early stages of PD and may adversely affect patients' functional status and well-being.

A sudden loss of the ability to start or sustain a specific motor activity (freezing) can also adversely affect performance in ADLs and subject the individual to more frequent falls ${ }^{17}$.

While there was no significant difference between the mild and moderate PD groups in the motor examination section of the UPDRS as a whole, analysis of each item showed that there was a significant difference in resting tremor, pill-rolling and bradykinesia between the groups. Bradykinesia, or slowness of movement, directly affects performance of activities such as turning in bed, standing up, getting dressed and walking ${ }^{2,15}$. It can be inferred from the results of the ADL section that the ability to perform activities related to personal hygiene is also affected.

Resting tremor, which is usually the first sign reported by individuals with $\mathrm{PD}^{15,16,17,18}$, was identified as the sign most closely associated with perceived worsening of the patient's health. Santos, Menezes and Souza ${ }^{19}$ reported that individuals in their series experienced embarrassment, particularly in connection with tremor because of its association with alcoholism. In addition to embarrassment, symptoms such as 
tremor and pill-rolling evolve in parallel with prejudice and reduced self-esteem and self-image, as they lead to shame, anxiety, a risk of depression, shyness in public spaces and social isolation $^{19}$.

Akinetic-rigid syndrome generally manifests when there has already been a $60 \%$ to $80 \%$ loss in dopaminergic neurons in the substantia nigra. Here, these symptoms were more important in individuals in the MOG, who had a mean disease duration of eight years, compared with three years in the $\mathrm{MIG}^{17,20}$.

The greatest impairment in terms of quality of life in the MOG was observed in the domains of mobility, stigma, cognition and ADLs, corroborating the findings of studies by Navarro-Peternella et al., ${ }^{9}$ Pinheiro et al., ${ }^{13}$ Navarro-Peternella and Marcon $^{14}$, and Quintella et al. ${ }^{21}$

In the mobility domain, having difficulty doing pleasurable leisure activities was one factor that adversely affected quality of life, a finding also reported in studies by Mandira ${ }^{22}$ and Tavares et al. ${ }^{23}$. Normal mobility is required to perform $\mathrm{ADLs}$ and leisure activities; reduced mobility compromises performance of these activities, limits the activities that can be performed and increases the time required to perform them. Individuals in the MOG also reported that they were confined to the home more than they would like, indicating that they are increasingly less able to perform activities outside their homes. Increasing physical impairment associated with the main symptoms of the disease causes individuals with $\mathrm{PD}$ to become isolated, while at the same time making them more dependent on others to perform activities that previously gave them a sense of personal satisfaction, in turn further reducing their quality of life ${ }^{13,24}$.

A greater dependence on others to carry out daily activities such as cutting food and drinking without spilling was a further factor in the decline in quality of life in these patients, particularly when the disease was in the moderate stage. Rigidity, bradykinesia and tremor impose limitations on these activities ${ }^{15}$, which in turn leads to irritability, anxiety, insecurity and pessimism as the individual is faced with the prospect of increasing dependence on others ${ }^{24}$.

Anxiety and concern about the future were significantly more important in the MOG, corroborating the study by Correia et al. ${ }^{20}$, showing that depressive symptoms, including anxiety, contribute to a decline in quality of life in these individuals. Navarro-Peternella and Marcon ${ }^{14}$ studied individuals with PD and found that fear and insecurity about dependence on others, about loss of independence at work and in ADLs and about the future in general, help to aggravate the condition. The individuals in their study reported that understanding the unstable nature of the disease and the fact that it was incurable is something that sadly they have to face for the rest of their lives and that will be part of their relationships and day-to-day activities.

More individuals in the MOG than the MIG reported avoiding situations that involved eating or drinking in public. This difference was statistically significant. Stigma in the MOG was an important social factor that adversely affected quality of life in the individuals assessed. Werle et al. ${ }^{25}$ investigated quality of life in individuals with cervical dystonia, a chronic disease that is also associated with stigma. They found that the need to hide the disease, insecurity in the presence of new people, problems with friends and family members, fear about the disease and sadness and irritation were factors that reduced their quality of life.

In our sample, problems related to concentration and poor memory were more significant in the MOG and progressively impaired quality of life, corroborating the study by Rodríguez-Violante et al. ${ }^{26}$ Motor symptoms are no longer considered the only important determinants of quality of life in individuals with PD, and the importance of non-motor symptoms, such as depression, apathy, fatigue, pain and cognitive deterioration, have been increasingly recognized ${ }^{9,17}$.

Here, the groups were similar in terms of gender, and the decline in quality of life among men was related to lack of support from friends and family members, corroborating the study by Navarro-Peternella and Marcon ${ }^{9}$. In a study by Tavares et al., ${ }^{23}$ the domain that evaluated social relations was a predictor of decline in quality of life in men with PD.

Quality of life among married individuals in our series was worse in the social support domain in both the mild and moderate stages. Among married individuals with moderate $\mathrm{PD}$, greater impairment of quality of life was also associated with stigma. This finding is unexpected as married individuals are normally considered to have greater support and acceptance. On the other hand, this finding may be explained by the fact that a chronic disease that causes increasing dependence can be a source of conflict and strengthen or weaken affective ties and family bonds ${ }^{14,27}$.

While in the present study older age among individuals in the moderate stage was related to worse scores for ADLs and cognition in the PDQ-39, in a study by Tedrus et al., ${ }^{28}$ the greatest impairment was observed for the ADL and mobility domains. Longer disease duration was associated with greater impairment of quality of life in the $\mathrm{ADL}$ and emotional well-being domains in the PDQ-39, a finding also reported in other studies ${ }^{26,29}$. In the study by Tedrus et al., ${ }^{28}$ a decline in quality of life in individuals with PD was associated not only with disease duration but also with advanced age and age of onset.

In conclusion, markers of decline in quality of life in the moderate stage of PD were related to stigma, worsening cognition, greater mobility impairment and reduced independence in ADLs. Drooling, a greater need for assistance with personal hygiene and a greater frequency of freezing caused significant quality-of-life impairment in individuals in the moderate stage of the disease together with resting tremor, pill-rolling and bradykinesia. 
1. Kalia LV, Kalia SK, Lang AE. Disease-modifying strategies for Parkinson's disease. Mov Disord. 2015;30(11):1442-50. https://doi.org/10.1002/mds.26354

2. Postuma RB, Berg D, Stern M, Poewe W, Olanow CW, Oertel W et al. MDS clinical diagnostic criteria for Parkinson's disease. Mov Disord. 2015;30(12):1591-601. https://doi.org/10.1002/mds.26424

3. Lees AJ, Hardy J, Revesz T. Parkinson's disease. Lancet. 2009;373(9680):2055-66. https://doi.org/10.1016/S0140-6736(09)60492-X

4. Souza A, Barreto MM, Santos SMS. [Evaluation of functional activity and quality of life in women with Parkinson's disease]. Saúde Pesqui. 2010;3(2):167-72. Portuguese.

5. Ferreira FD, Ferreira FMD, Heleno RB, Mella-Júnior SE. [Parkinson's disease: physiopathologic and therapeutic aspects]. Saúde Pesqui. 2010;3(2):221-8. Portuguese

6. Silva PFC, Pereira RPR, Silva SM, Corrêa JCF, Corrêa FI. [Correlation between clinical profile, quality of life and disability of the patients of Associação Brasil Parkinson]. ConScientiae Saúde. 2010;10(4):650-6. Portuguese. https://doi.org/10.5585/conssaude.v10i4.3095

7. Martinez-Martín P, Damián J. Parkinson's disease: depression and anxiety in Parkinson's disease. Nat Rev Neurol. 2010;6:243-5. https://doi.org/10.1038/nrneurol.2010.49

8. Hoehn MM, Yahr MD. Parkinsonism: onset, progression and mortality Neurology. 1967;17(5):427-42. https://doi.org/10.1212/WNL.17.5.427

9. Navarro-Peternella FM, Marcon SS. Quality of life of a person with Parkinson's disease and the relationship between the time of evolution and the severity of the disease. Rev Lat Am Enfermagem. 2012;20(2):384-91. https://doi.org/10.1590/S0104-11692012000200023

10. Fahn S, Elton R. Members of the UPDRS. Development Committee. The unified Parkinson's disease rating scale. In: Fahn S, Marsden CD, Calne DB, Goldstein M, editors. Recent developments in Parkinson's disease. New York: McMellam Health Care Information; 1987. p.153-63.

11. Peto V, Jenkinson C, Fitzpatrick R, Greenhall R. The development and validation short measure of functioning and well being for individuals with Parkinson's disease. Qual Life Res. 1995;4(3),241-8. https://doi.org/10.1007/BF02260863

12. Borges AEA, Mendes LM, Lemos MTM. [Physiotherapeutic perception of parkinsonian individuals correlating assessment scales]. Rev Bras Ci Saúde. 2014;18(3):187-94. Portuguese. https://doi.org/10.4034/RBCS.2014.18.03.01

13. Pinheiro IM, Santos LLS, Paula LCN, Costa ACN. [Impact of Parkinson's Disease in functionality and quality of life of elderly in a geriatric unit reference in the city of Salvador Bahia]. Rev Ciênc Méd Biol. 2014;13(3):292-7. Portuguese. https://doi.org/10.9771/cmbio.v13i3.12933

14. Navarro-Peternella FM, Marcon SS. [Living with Parkinson's disease from the perspective of parkinsonians and their relatives]. Rev Gaúcha Enferm. 2010;31(3):415-22. Portuguese. https://doi.org/10.1590/S1983-14472010000300002
15. Soares GS, Peyré-Tartaruga LA. [Parkinson's disease and physical exercise: a literature review]. Cien Movimento. 2011;12(24):69-85. Portuguese. https://doi.org/10.15602/1983-9480/cmbs.v12n24p69-85

16. Khoo TK, Yarnall AJ, Duncan GW, Coleman S, O'Brien JT, Brooks DJ et al. The spectrum of nonmotor symptoms in early Parkinson disease. Neurology. 2013;80(3):276-81. https://doi.org/10.1212/WNL.0b013e31827deb74

17. Massano J. [Parkinson's disease: a clinical update]. Acta Med Port. 2011;24(84):827-34. Portuguese.

18. Souza CF, Almeida HC, Sousa JB, Costa PH, Silveira YSS, Bezerra JC. [Parkinson's disease and the process of aging motor: literature review]. Rev Neurocienc. 2011;19(4):718-23. Portuguese.

19. Santos ISC, Menezes MR, Souza AS. [Elderly people's conceptions of living with Parkinson's disease]. Rev Enferm UERJ. 2009;17(1):69-74. Portuguese.

20. Correia MGS, Paixão AO, Jesus AVF, Silva FS, Messias GMS, Nunes TGM et al. Doença de Parkinson: uma desordem neurodegenerativa. Cad Grad Ciênc Biol Saúde. 2013;1(16):57-65.

21. Quintella RS, Sachetti A, Wibelinger LM, Oliveira SG. Qualidade de vida e funcionalidade na doença de Parkinson. RBCEH. 2013;10(1):104-12. https://doi.org/10.5335/rbceh.2012.1823

22. Mandira ALS. [Study of positive influence on quality of life patients with Parkinson's Disease participants Group Lotus]. Kairós Gerontol. 2012;15(4):185-99. Portuguese.

23. Tavares DMS, Dias FA, Santos NMF, Haas VJ, Miranzi SC. Factors associated with the quality of life of elderly men. Rev Esc Enferm USP. 2013;47(3):678-85. https://doi.org/10.1590/S0080-623420130000300022

24. Vara AC, Medeiros R, Striebel VLW. [Physical therapy in Parkinson's disease]. Rev Neurocienc. 2012;20(2):266-72. Portuguese.

25. Werle WR, Takeda SYM, Zonta MB, Guimarães ATB, Teive HAG. The physical, social and emotional aspects are the most affected in the quality of life of the patients with cervical dystonia. Arq Neuropsiquiatr. 2014;72(6):405-10. https://doi.org/10.1590/0004-282X20140044

26. Rodríguez-Violante M, Cervantes-Arriaga, A, Corona T, Martínez-Ramírez D, Morales-Briceño H, Martínez-Martín P. Clinical determinants of health-related quality of life in Mexican patients with Parkinson's disease. Arch Med Res. 2013;44(2):110-4. https://doi.org/10.1016/j.arcmed.2013.01.005

27. Cetolin SF, Trzcinski C, Mahl AC, Steffani JÁ, Luccas TN, Presta AA. Alterações Sociofamiliares na vida de pessoa com mal de Parkinson usuárias da saúde pública. UNOESC Ciência - ACHS. 2012;3(2):203-12.

28. Tedrus GMAS, Fonseca LC, Kange PM. Parkinson's diseasei of clinical and cognitive aspects on quality of life. Dement Neuropsychol. 2010;4(2):131-7. https://doi.org/10.1590/S1980-57642010DN40200010

29. Filippin NT, Martins JS, Libera LBD, Halberstadt BF, Severo AR. [Quality of life of subjects with Parkinson's disease and caregivers]. Fisioter Mov. 2014;27(1):57-66. Portuguese. https://doi.org/10.1590/0103-5150.027.001.A006 